ЮЛИНА Галина Николаевна - кандидат педагогических наук, доцент; директор Института социально-гуманитарных технологий Московского государственного университета технологий и управления им. К.Г. Разумовского (ПКУ) (109004, Россия, г. Москва, ул. Земляной Baл, 73; UlinaGN@ mgutm.ru)

АДРИАНОВА Светлана Константиновна - магистрант Института социально-гуманитарных технологий Московского государственного университета технологий и управления им. К.Г. Разумовского (ПКУ) (109004, Россия, г. Москва, ул. Земляной Вал, 73; lanadrian@таil.ru) МАРТЫНЮК Галина Валерьевна - магистрант Института социально-гуманитарных технологий Московского государственного университета технологий и управления им. К.Г. Разумовского (ПКУ) (109004, Россия, г. Москва, ул. Земляной Baл, 73; ga_la_ma@таil.ru)

\title{
ОСОБЕННОСТИ МЕЖЛИЧНОСТНЫХ ОТНОШЕНИЙ В КОЛЛЕКТИВЕ, ОРГАНИЗАЦИИ
}

Аннотация. В статье рассматривается проблема конфликтов во взаимоотношениях в коллективе и в организации в целом в свете современных представлений о нейропластичности мозга, показаны возможности работы с этим качеством мозга как перспективное направление в развитии психологии, соционики и конфликтологии. Дается оценка использования данной концепции для повышения качества жизни пожилых людей. Для решения этих задач авторы подробно останавливаются на одной из психологических типологий - теории уровней абстрактного интеллекта (ТУАИ) Я. Фельдмана.

Ключевые слова: психология, соционика, конфликтология, нейропластичность мозга, теория уровней абстрактного интеллекта, московский проект «Серебряный университет»

A ктуальность данной проблемы назрела в связи с изучением некоторых аспектов, влияющих на отношения в коллективе, производительность труда, трудопотери ввиду частых обращений к врачам или, наоборот, боязни обращения за медицинской помощью в связи с психосоматическим состоянием. Вследствие этого падает концентрация внимания, ухудшается возможность переключения на разные виды деятельности в рамках решения данной проблемы, страдают организация и планирование работы, возникают неэффективные межличностные отношения - все эти и другие проблемы напрямую связаны с нейропластичностью мозга.

О том, что мозг пластичен, высказывался еще в 1890 г. Уильям Джеймс (William James), американский философ и психолог, в своем труде «Принципы психологии». Пластичный - значит способный к изменению, обучению. Однако это свойство он считал присущим только детскому мозгу [Петровская 1991: 54-55].

В начале 40-х гг. XX в. доктор наук, инженер, физик Моше Фельденкрайз (Moshe Feldenkrais) благодаря глубокому анализу факторов, имеющих место в процессах человеческого развития и обучения, создал метод работы, использующий фокусированное внимание и движение, который помог тысячам людей преодолеть последствия аварий, болезней и травм [Feldenkrais 1981: 9]. Уроки в методе Фельденкрайза представляют собой грамотно выстроенные последовательности движений, созданные для наибольшей эффективности обучения за счет использования интереса, новизны возникающих задач и их постепенного усложнения [Фельденкрайз 2003: 14] (как было обнаружено позже, именно такие качества стимулируют пластичность мозга). Уроки выполняются с полным вниманием, которое тоже в буквальном смысле «меняет» мозг, они воспроизводят комплексные нелинейные стратегии, которые мы осваиваем в процессе моторного развития с момента рождения до 10 лет. Все эти факторы в совокупности способствуют развитию более высокого уровня самоор- 
ганизации и совершенствованию навыков. М. Фельденкрайз спрогнозировал пластичность мозга исходя из собственной работы с людьми, наблюдений за детьми, обучающимися движению, а также из анализа огромного числа научных источников. Он не достиг бы успеха, если бы мозг изначально не обладал свойством пластичности и способностью усваивать новые способы совершения действий.

Но эта концепция оставалась недоказанной до тех пор, пока Фельденкрайз не встретил другого ученого - доктора Пола Бах-и-Рита в конце 1970-х гг. Пол Бах-и-Рита1 ${ }^{1}$ Paul Bach-y-Rita), доктор и кандидат наук, нейрофизиолог, был уверен в пластичных свойствах мозга задолго до того, как их существование можно было доказать и нейропластичность стали принимать во внимание в исследованиях мозга. Он был во многом отцом идеи нейропластичности и изучал это явление у людей с нарушениями функций мозга. Но открытие нейропластичности не было оценено и не применялось в науке и реабилитации в 1970-1980-х гг. нигде, кроме метода Фельденкрайза и двух пилотных проектов по восстановлению от инсультов и травм головы (в 1975 и 1978 гг.).

Двое ученых из очень разных областей науки предположили наличие свойства нейропластичности и обнаружили, что мозг способен на гораздо большее, чем долгое время считалось, а затем использовали это свойство на практике, каждый своим путем. Однако до 1990-х гг. исследования нейропластичности не представляли интереса для других ученых.

Нейропластичность - это способность нейронов и нейронных сетей в мозге изменять связи и поведение в ответ на новую информацию, сенсорное стимулирование и другой опыт. Эта способность имеет прямой практический эффект, который знаком многим, но лишь недавно стал предметом целенаправленных исследований [Хокинг 2017а: 62]: наш мозг любит учиться. До 1998 г. считалось, что мы рождаемся с миллиардами нейронов, которые постепенно отмирают с возрастом и что новые клетки никогда не создаются. На самом деле мы рождаемся и умираем с миллионами неиспользуемых, несформированных стволовых клеток в нашем мозге. Потенциал к преобразованию данных клеток в нейроны существует в течение всей нашей жизни, раздвигая границы того, что мы прежде считали невозможным, особенно в области здоровья и восстановления от травм и заболеваний [Франс 2007: 156]. Нейробиолог Лара Бойд ${ }^{2}$ (Lara Boyd) и доктор медицины, психиатр, психоаналитик Норман Дойдж (Norman Doidge) заверяют, что нейропластичность - ключ ко всем изменениям: это способность мозга изменять себя на протяжении всей жизни. Метаморфозы могут быть как физическими, так и функциональными; происходить под влиянием факторов как внешней среды, так и внутренней [Дойдж 2019: 54, 344].

Итак, концепция нейропластичности мозга является весьма новым видением, ведь раньше ученые считали, что данный орган имеет возможность изменяться только в раннем возрасте и теряет эту способность во взрослой жизни. Чтобы чему-либо научиться, необходимо сфокусировать внимание на стоящей перед вами задаче. Концентрация и практика новых занятий вызывает изменения мозга, создание новых связей между миллиардами клеток и выработку сенсорно-моторных карт для каждой новой деятельности. Даже когда вы просто представляете себе движение, визуализируя его в уме, изменения мозга могут быть измерены и видимы на позитронно-эмиссионной томографии [Хокинг 2017б: 58]. Клетки мозга и нервы изменяют свой внешний вид и

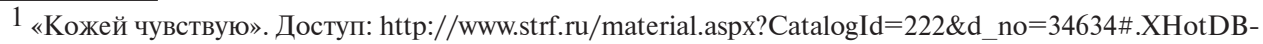
hpHx; https://neyroport.ru/istoriya/ (проверено 01.03.2019).

2 Lara Boyd «How we learn?»: лекция на TEDx Talks. Доступ: https://youtu.be/LNHBMFCzznE (проверено 01.03.2019).
} 
функции, растут, уменьшаются, соединяются друг с другом совершенно новым образом и разрывают старые связи, обмениваются обязанностями и функциями - все это позволяет нам использовать части мозга для непривычных задач, осваиваться в различных ситуациях, возникающих в течение насыщенной событиями жизни.

Но как же это связано с межличностными отношениями и вообще с нашей жизнью?

Мы часто говорим об эффективности чего угодно. А как измерить эффективность человеческой жизни, особенно с точки зрения бизнес-планирования? Как можно менять жизненную эффективность, и какие факторы на это влияют? Статистика в разных странах разная, и это всего лишь цифры, которые существенно отличаются по регионам проживания даже в одной стране. Итак, возьмем для удобства среднестатистического человека, который живет в Москве и его активный трудовой возраст в среднем - 60 лет. А дальше что? Интересная ситуация: часть людей с накопленным опытом и нейропластичностью мозга начинают активно учиться и переосмысливать свои «догмы», примером могут служить студенты московского проекта «Серебряный университет». Они продолжают эффективно работать, и за счет своих новаторских идей и профессионализма остаются «своими» даже среди молодых сотрудников. А часть людей блокируют свой интеллект и творческий разумный подход к работе из-за повышенной тревожности и неадаптивных отношений с руководством и коллективом.

Рассмотрим другой аспект - молодого сотрудника на производстве. Есть такая практика, как испытательный срок на работе, призванная помочь адаптироваться сотруднику в новом коллективе, ознакомиться со спецификой работы. Один сотрудник ходит с блокнотом и все фиксирует, расширяет свой кругозор и налаживает контакт с коллегами, другой из-за повышенной мнительности или придирчивости к окружающим лишает себя опыта познания [Филатов и др. 2017: 207].

Конечно, назрела необходимость психологической работы, настоящей, а не формально-анкетной, чтобы учитывать и правильно подбирать сотрудников с учетом возможностей их самореализации в данном деле. При этом надо учитывать психотипы людей. Наиболее актуальны и популярны типология Юнга, типология Майерс-Бриггс (MBTI), психософия, типология пяти травм (Лиз Бурбо), типология стилей мышления, теория уровней абстрактного интеллекта (ТУАИ) и т.Д. [Ануров, Латышев 2017: 7].

Рассмотрим только одну из психологических типологий - теорию уровней абстрактного интеллекта (ТУАИ), автором которой является Яков Фельдман [Ануров, Латышев 2017: 8-29]. Согласно ТУАИ, каждый уровень соответствует тому, какую часть мира человек способен удерживать в своем поле зрения. Чем выше уровень человека, тем большую часть мира он способен видеть и тем более высокие ценности способен исповедовать, что, в свою очередь, увеличивает нейропластичность его мозга, а значит и работоспособность.

На первом уровне человек способен удерживать во внимании всего один объект, и социум - слишком сложная для него структура. Не всегда внимание на первом уровне означает низкий интеллект, часто некоторые намеренно снижают свой уровень до первого «хочу - беру», чтобы не считаться со сложностями мира, общество ими воспринимается как «толпа» [Аралова 2011: 52].

На втором уровне удерживается уже несколько объектов внимания, а мир делится на «своих» и «чужих», хорошее и плохое, выгодное и невыгодное. Основные проблемы этого уровня - ксенофобия, иногда доходящая до пол- 
ной ненависти, неприятие чужаков. Такие люди часто доводят себя до неврозов.

На третьем уровне человек видит множество упорядоченных объектов. Концентрация внимания связана с достижением целей и способностью охватить весь процесс и ценности, которые связаны со временем. Это первый социальный уровень, для которого характерна жесткая иерархическая структура.

Взаимодействия людей третьего и второго уровней часто конфликтны, т.к. третий уровень пытается выдернуть человека из комфортного второго уровня и вручить ему какую-нибудь цель. Часто у конфликтующих могут быть заболевания аутоиммунной этиологии (неприятие себя как чужеродного организма: аллергии, бронхиальная астма и т. д.)

На четвертом уровне человек охватывает вниманием уже несколько процессов одновременно. Если человек застрял в детском или подростковом периоде, то он начинает массово терять внимание, что связано с невозможностью удерживать концентрацию и выполнять множество социальных ролей. Именно «четверка» способна осознать свою роль в коллективе и может удержать внимание не только на процессе своей деятельности, но и на процессе деятельности других людей, их ролей. Ярко выраженных ролей в «тройке» нет, есть только иерархия и тотальная конкуренция. Поэтому по сравнению с ней «четверка» выглядит иначе, и с третьим уровнем у нее часто возникают конфликты, т.к., по мнению «тройки», ничего нового привносить не надо - все и так хорошо и ясно. Несмотря на косность мышления, люди третьего уровня могут влиять на четвертый, для которого характерны нестандартные идеи и пути решения проблем.

Уровень пятый - это новый качественный скачок, на котором внимание направлено не только на все хорошо исследованное, но и на решения, которые лежат в стороне от протоптанных дорог. Это руководители со своим стилем игры, которые формируют свою команду. И это первый надсоциальный уровень. Вместо следования заданным линиям поведения идет творческий подход, который ломает привычные шаблоны. В реальном мире «пятерки» часто нестабильны, они часто опираются на четвертый уровень, т.к. риск у них граничит с анархией, но, если не нарушаются юридические законы, это уровень одного стиля, одной культуры, одной стратегии. При конфликте между 4-м и 5-м уровнем люди 5-го уровня часто уходят в депрессию, патомимию (самоповреждающее поведение) [Кулаков 2017: 68], они часто занимаются экстремальными видами спорта.

Шестой уровень способен охватывать несколько стратегий, несколько стилей поведения, он развивает и дополняет их все, пока не придет к логическому завершению. Именно люди 6-го уровня склонны к теории и доказательству, они мыслят объемно и во всем пытаются увидеть глубину, но в отличие от «пятерок» риск не любят. В основном конфликты из-за этого.

На седьмом уровне человек выводит мышление на новый уровень. «Семерки» будто связываются с реальностью напрямую, не опираясь на модели в голове. Это люди с высоким интеллектом, интуицией и непредсказуемые. Их проблема - одиночество, и поэтому они иногда вынуждены отступать от своих взглядов и сдаваться обществу.

Восьмой уровень внимания шире, чем одно мировоззрение. Это уровень подлинного гуманизма и милосердия, т.к. много времени уделяется не только своим, но и чужим ценностям.

Есть еще и девятый уровень - абстрактный, недостижимый для человека уровень, на котором объектом внимания становится весь мир одновременно. 
Чаще всего столкновение двух равных или нечетных уровней (1-й, 3-й, 5-й, 7-й) - поле для конкурентной игры. Выход в том, что людям необходимо обратить внимание на свою и чужую цель, на свое и чужое мировоззрение. Четные уровни (2-й, 4-й, 6-й, 8-й) изначально способны к взаимопониманию, и зона для их конфликтов не такая явная, потому что они взаимообогащаются. При столкновении соседних - нечетного и более высокого четного уровней (1-2-й, 3-4-й, 5-6-й, 7-8-й) - принимается во внимание материальная и социальная часть мира, а также культурная и духовно-мировоззренческая. В таком противостоянии четный старший уровень является наставником для нечетного. Столкновение соседних уровней четного и более высокого нечетного уровней (2-3-й, 4-5-й, 6-7-й) - более драматично и эмоционально насыщено, т.к. старший нечетный уровень всегда исповедует кардинально иные ценности, чем младший четный.

Конечно, это лишь одна из частей необъятных знаний психологии, которые помогают приоткрыть проблему конфликтов во взаимоотношениях и перспективное направление в развитии не только наук психологии, соционики и конфликтологии, но и новой медицины, которая идет к истокам болезней и обеспечивает новый уровень качества жизни, что важно для роста качества межличностных отношений и для самооценки каждого человека.

\section{Список литературы}

Ануров Д., Латышев А. 2017. От соционики до теории уровней: восемь самых интересных типологий. М.: Медков С.Б. 208 с.

Аралова Е.В. 2011. Сознание в контексте виртуального мира. - Власть. № 3. C. 51-54.

Дойдж Н. 2019. Пластичность мозга. Потрясающие факты о том, как мысли способны менять структуру и функции нашего мозга. М.: Эксмо. 544 с.

Кулаков С.А. 2017. Основы психосоматики. М.: Медицина. 537 с.

Петровская Л.А. 1991. К столетию «Принципов психологии» У. Джеймса. М.: Педагогика. 368 с.

Хокинг С. 2017а. Краткие ответы на большие вопросы. М.: Эксмо. 256 с.

Хокинг С. 2017б. Краткая история времени. М.: АСТ. 232 с.

Фельденкрайз М. 2003. Искусство движения. Уроки мастера (пер. с англ. А. Заславской). М.: Эксмо. 352 с.

Филатов В.В., Алексеев А.Е., Дорофеев А.Ю., Долгова В.Н., Женжебир В.Н., Колосова Г.М., Положенцева И.В., Лочан С.А., Пшава Т.С., Фадеев А.С., Шестов А.В. 2017. Управленческое консультирование: менеджмент-консалтинг. Курск. 338 с.

Франс А. 2007. Психосоматическая медицина. М.: Эксмо-Пресс. 523 с.

Feldenkrais M. 1981. Body and Mature Behaviour. N.Y.: International Universities Press Inc. 167 p. 
YULINA Galina Nikolaevna, Cand.Sci. (Ped.), Associate Professor; Director of the Institute of Social and Humanitarian Technologies, K.G. Razumovsky Moscow State University of Technologies and Management (the First Cossack University) (73 Zemlyanoi Val St, Moscow, Russia, 109004; UlinaGN@mgutm.ru)

ADRIANOVA Svetlana Konstantinovna, Master Student at the Institute of Social and Humanitarian Technologies, K.G. Razumovsky Moscow State University of Technologies and Management (the First Cossack University) (73 Zemlyanoi Val St, Moscow, Russia, 109004; lanadrian@mail.ru)

MARTYNYUK Galina Valer'evna, Master Student at the Institute of Social and Humanitarian Technologies, K.G. Razumovsky Moscow State University of Technologies and Management (the First Cossack University) (73 Zemlyanoi Val St, Moscow, Russia, 109004; ga_la_ma@mail.ru)

\title{
FEATURES OF INTERPERSONAL RELATIONS IN A TEAM AND ORGANIZATION
}

\begin{abstract}
The article deals with the problem of conflicts in relationships in a team and in the organization as a whole in the light of modern ideas about brain neuroplasticity. The authors show the possibilities of working with this quality of the brain as a promising direction in the development of psychology, socionics and conflictology and give an assessment of the use of this concept to improve the quality of life of the elderly. To solve these problems, the authors dwell on the theory of abstract intelligence levels (TAIL) by J. Fel'dman.

Keywords: psychology, socionics, conflictology, brain neuroplasticity, theory of abstract intelligence levels, Moscow Silver University Project
\end{abstract}

